however, affects later choice of partners, as does also the adequacy of mothering in mother-reared infants, suggesting that the maintenance of attachment depends on the quality of social feedback. Much of this material has not been published previously.

Sorenson's chapter provides a review of many aspects of the anatomy, physiology and behaviour of tree shrews, and includes much new material. Their taxonomic position is honestly recognized as transitional. The literature on behavioural abnormalities in primates is reviewed by Mitchell. A large part of the chapter is concerned with the abnormalities encountered after various conditions of social deprivation at the Wisconsin laboratory, but much other material is included. Finally, the results of 1,250 hours of field observation on Presbytis johnii are brought together by Poirier-a valuable contribution to our knowledge of field behaviour and ecology.

If these standards are maintained, this series should do much to bridge the present gap between experimentalist and field worker. ROBERT A. HINDE

\section{Ecologist on the Farm}

Grassland Ecology. By C. R. W. Spedding. Pp. xii +221 . (Clarendon: Oxford; Oxford University: London, March 1971.) $£ 2.00$.

THIs book is described as "a functional anatomy of grassland ecology for readers who may be specialists in some of the components but relatively new to others". The acceptable thesis is advanced that grassland ecology is a complex ecosystem in which climate, soil, plants and grazing animals are major interacting parts, each of which in turn is composed of interacting sub-components. Most grassland research workers pay lip service to this concept, but for various reasons concentrate their work on component parts in isolation, thereby limiting its relevance to the ecosystem. The author has applied an ecological approach to grassland knowledge and, in effect, has constructed a basic model of the grassland ecosystem.

Seven chapters deal with plant component parts of the model, starting with the individual plant, moving to swards, both cultivated and natural, and ending with the factors affecting the efficiency of primary production. The lack of precision in grassland terminology is decried and it is also stressed that selected processes should not be studied to the exclusion of others equally important. The author notes lack of knowledge on legume senescence and decay in spite of its importance as a source of nitrogen; on how to improve the quantity of nitrogen in circulation in the ecosystem; and on the soil and its processes. The brevity of chapter 6 on natural grassland is sur- prising, even though there may be no fundamental difference between natural and sown grassland. Most of the world's grasslands are natural plant communities which sustain a large proportion of the domestic grass-eating animals.

Eight chapters are concerned with the fauna of grassland and their interactions with grassland populations. Basic concepts of efficiency in secondary production and the major factors affecting this efficiency are dealt with. Grassland herbage offers a virtually complete diet for the ruminant. Only when much higher performance (of growth, milk yield or reproduction) is required may herbage be inadequate, usually in its content of digestible energy.

The remaining five chapters of the book are devoted to the efficiency of production from grassland of milk, meat, wool and hides and to a brief philosophical discussion of the past and potential contribution of grassland to man. Because of the complexity of model building and the need to use quantitative as well as descriptive language, mathematical models of real or simulated data can be built up with the aid of the computer. A useful appendix has been included to show how this can be done.

Throughout the book, the author seeks to draw distinctions between the simplicity of agricultural efficiency measures and the complexity of ecological assessment. It is also noted that the ecosystem approach need not be so complex as is commonly believed since, for example, non-limiting component parts of the model need not be studied in depth. A plea is made for more understanding of ecological principles in order to understand how they may be more fully utilized by the agricultural systems. (In practice, the farmer has always been an applied ecologist.)

The material in the book is well organized and useful lists of references are given at the end of each chapter: author and subject indexes are provided. Editorial lapses are few, mainly in the contents, but in the text, tables and figures the units of energy, mass/unit area and force used do not always accord with recommended SI unit terminology. Overall, the author's ecological approach in the book is successful and a coherent account of the basic grassland ecosystem has been produced at a moderate price. The book can be recommended to all those interested in the role of ecology in the biological sciences. JoHn Frame

\section{Mammals Observed}

The Life of Mammals. Vol. 2. By.L. Harrison Matthews. Pp. $440+30$ plates. (Weidenfeld and Nicolson: London, March 1971.) £4.25.

THis second volume of Dr Matthews's account of various aspects of mam- malian life reviews the orders and families of mammals with the exception of the Primates. The fourteen chapters progress in an orthodox manner from monotremes and marsupials to cattle and sheep. Except for some rare bats and rodents about which little is known, all the genera of living mammals obtain a mention. The descriptions are chiefly concerned with the habitats, behaviour, ecology and ethology of various mammalian types. Care has been taken to avoid overlap with the topics covered in volume 1 , but this means that nowhere in volume 2 is there a complete discussion of the overall characteristics of a genus and the reader must return to volume 1 for fuller consideration of reproduction, adaptation, migration and behavioural aspects. Anatomical and descriptive material has been deliberately reduced to a minimum, just enough to give an impression of the appearance of each type. Where, however, the anatomical adaptations afford "a very pleasant sight", as Edward Tyson remarked on seeing the construction of a porpoise, there is no hesitation to expand the description.

It is impossible not to share with $\mathrm{Dr}$ Matthews his delight in observing living mammals and in collecting information and first hand accounts on their habits. $\mathrm{He}$ discusses whether it is true that hedgehogs carry off fruit by impaling it on their spines and comments on their resistance to wasp stings and strikes by adders. We learn how moon rats can be caught in traps baited with bananas and how the pygmy anteater gives a peculiar little sneeze when startled. Many of the curious behavioural manifestations of living mammals are commented upon in a lucid, lively and informative style. The account is, however, by no means limited to a "believe it or not" description of mammalian antics. There is much solid comparative anatomy, embracing skeletal characteristics and general morphology, consideration of functional aspects such as antler shedding, delayed implantation, and constipation in sloths. Dr Matthews also adds much on dentitions but is at a loss to ascribe a function to a narwhal's tusk: perhaps some illustrations of the great variety of tooth form in mammals would have been helpful.

There are some sketches of a few mammals, of a number of heads, and of some morphological features: most readers will wish for more. The thirty plates are all instructive in one way or another, even about the fur coats of big cats, but some indication of size is needed in a few. Many years ago, D'Arcy Thompson wrote a letter to The Times regretting that scholarship candidates knew so little about the commoner animals of their world. Here is a book about common and rare mam- 